Index Copernicus Value: 71.58

ISSN (e)-2347-176x ISSN (p) 2455-0450

crossref DOI: _https://dx.doi.org/10.18535/jmscr/v5i9.05

\title{
Comparison of Lignocaine, Diltiazem and Combination for Controlling the Cardiovascular Responses to Tracheal Intubation-A Cohort Study
}

\author{
Authors \\ Dr Rajan Babu", Dr Sugandha ${ }^{2 *}$ \\ ${ }^{1}$ Associate Professor, Department of Anaesthesiology, Mount Zion Medical College, Adoor \\ ${ }^{2}$ Associate Professor, Department of Anesthesiology, Gokulam Medical College, Trivandrum \\ *Corresponding Author \\ Dr Sugandha \\ Associate Professor, Department of Anesthesiology, Gokulam Medical College, Trivandrum
}

\begin{abstract}
Endotracheal intubation has turned out to be a routine procedure in the modern-day anesthesia care by the middle of the last century. However, this procedure results in transient cardiovascular changes, which could result in potential complication in physiologically deranged population. We conducted this study to compare the effects of two drugs, namely lignocaine and diltiazem alone and in combination in attenuating the deleterious effect of intubation on cardiovascular system. The setting of this prospective comparative study was government medical college Thiruvananthapuram. We studied 45 cases of ASA Gr. I \& II between age groups 20-65 years, involving both sexes coming for major elective surgical procedures. Each group consisted of 15 patients. Heart rate, systolic and diastolic blood pressures were monitored at different time points. We analyzed the data with stata IC 15 software. The outcome measures were compared with repeated measures ANOVA. The median age with inter quarter range of the patients was 36(28-45) years. There were more females in the study groups (80percent). Systolic and diastolic pressure varied at different time points in the groups studied, within the groups and across the groups. Systolic and mean arterial pressure showed initial rise and later a downward trend across the group. There was a statistically significant difference between the three groups studied $(p<0.05)$. The study revealed that SBP, DBP and MAP increased briefly after tracheal intubation in all patients who had received lignocaine, diltiazem or diltiazem plus lignocaine before intubation.

Keywords: Blood Pressure, Heart Rate, Lignocaine, Diltiazem, Laryngoscopy, intubation, Prospective Studies, Anaesthesia.
\end{abstract}

\section{Introduction}

Endotracheal intubation has turned out to be a routine procedure in the modern day anesthesia care by the middle of the last century ${ }^{1}$. The most popular general anaesthetic technique of the present day is endotracheal intubation following direct laryngoscopy after intravenous induction and muscle relaxation ${ }^{2,3}$. This procedure of endotracheal intubation produces reflex cardiovascular responses in the form of tachycardia and hypertension, which has been recognised since $1951^{4,5}$. Laryngotracheal stimulation leads to sympathetic adrenal stimulation ${ }^{5-7}$. The rise in pulse rate and blood pressure are usually short-term and most often without any hazardous consequences in healthy individuals ${ }^{8,9}$. 
The maximum change in the blood pressure occurs at the insertion of an endotracheal tube ${ }^{10}$. However, these transient changes can alter the balance between myocardial oxygen demand and supply leading to arrhythmias, ischemia and infarction in those with hypertension, coronary artery and cerebrovascular diseases ${ }^{11-13}$.

These physiological considerations imply the importance of attenuating the increase in heart rate and blood pressure rise due to endotracheal intubation. This is usually accomplished by pretreatment with various agents like lignocaine, nicardipine, verapamil and diltiazem ${ }^{14-19}$. The present study is to compare the effect of two different drugs viz. diltiazem (a calcium-channel blocker) and lignocaine (a local anaesthetic with anti arrhythmic properties) when given together, with the effect of these two individual drugs when they are given individually for attenuating the cardiovascular response to laryngoscopy and tracheal intubation in the form of changes in systolic pressure, diastolic pressure and mean arterial pressure.

\section{Materials and Methods}

We conducted this comparative study in the department of anesthesia, Govt. medical college, Thiruvananthapuram, during the period April 1999 to September 1999. Informed consent was taken from every patient enrolled into this study. Moreover, we maintained the confidentiality of the patient at every stage of the study. We started recruiting the participants into the study only after getting the approval from the ethics committee of the medical faculty, Govt. medical college, Thiruvananthapuram.

We studied 45 cases of ASA Gr. I \& II between age groups 20-65 years involving both sexes coming for major elective surgical procedures like thyroidectomy, mastectomy, orthopaedic procedures and laparotomies with 15 patients in each group. A prior sample size calculation was done and fixed at 45 . We recruited 15 consecutive patients from each group. All patients of age between 20 and 65 were included in the study. Patients with a Mallampatti score of I or II and of
ASA grade I \& II were only included in the study. Patients with hypertension were excluded. Moreover, those patients with serious systemic illness and those with history of myocardial infarction, bradycardia, ECG changes or arrhythmia were not recruited into the study. 45 patients of the present study were put into 3 groups;

1.A study group with lignocaine who received 1.5 $\mathrm{mg} / \mathrm{kg}$ of the drug as IV bolus.

2.A study group with diltiazem who received 0.2 $\mathrm{mg} / \mathrm{kg}$ of the drug as IV bolus.

3.A study group with diltiazem - lignocaine combination where both drugs are given IV, in the same dose as given in groups, I and II.

Tab Diazepam 10mg was given to all the patients under study, on the night before surgery for purpose of anxiolysis. Weight of the patients was recorded in the premedication room. All patients received Inj.Morphine in a dose of $0.1 \mathrm{mg} / \mathrm{kg}$ and Inj.Promethazine $0.5 \mathrm{mg} / \mathrm{kg}$ intramuscularly 45 minutes prior to anticipated time of induction.

For all patients, an intravenous line was established on the forearm with a $18 \mathrm{G}$ cannula and a drip of $5 \%$ dextrose in water was started. Blood pressure cuff was applied to the other upper arm; ECG monitor was attached to all patients, which displayed heart rate and continuous ECG tracing. A pulse oximeter was also attached to watch for any hypoxemia during the procedure. Thereafter the baseline heart rate, systolic and diastolic blood pressure were recorded. The drugs and the variables under study were recorded at definite time intervals. During the study period, patients were not manipulated or subjected to any surgical stimulation. Induction technique was similar in all patients.

All the patients were pre-oxygenated for $3 \mathrm{~min}$. Then (at zero min) thiopentone sodium in a dose of $5 \mathrm{mg} / \mathrm{kg}$ was given IV over $30 \mathrm{sec}$. Over the next $30 \mathrm{sec}$, the test drug (diltiazem or lignocaine or lignocaine-diltiazem combination) was given, and it was followed by succinyl choline in a dose of $2 \mathrm{mg} / \mathrm{kg} \mathrm{IV}$. Once the muscle twitching is over the heart rate, and systolic and diastolic blood pressures were measured i.e at, nearly $2 \mathrm{~min}$ of 
induction, while respiration was assisted using mask ventilation with oxygen. At $2 \mathrm{~min}$ of induction and mask ventilation with oxygen, a gentle direct laryngoscopy was done using a Macintosh curved bladed laryngoscope, and trachea was intubated using a proper sized cuffed endotracheal tube. The laryngoscopy and intubation were done by the principal investigator in all the patients and parameters were measured at three, four, five, six and seven minutes of the study period. Anaesthesia was maintained with nitrous oxide and oxygen in the ratio 2:1 along with halothane $0.5 \%$ and vecuronium was used as the muscle relaxant of choice because of its relative cardiostability.

All data were recorded in a pretested case report form by the principal investigators. Baseline pulse rate, blood pressure were recorded and routine examination of blood and urine done. X-ray chest and ECG were taken. Selected patients had normal hemoglobin, ECG and X-ray chest. The variables $\mathrm{HR}, \mathrm{SBP}$ and $\mathrm{DBP}$ were recorded immediately after intubation and afterwards at one-minute intervals till 5 minutes of intubation.

All patients were monitored with continuous ECG tracing, pulse oximetry and heart rate and blood pressure recording every 10 minutes till the end of surgery. At the end of surgery patients were reversed with $0.05 \mathrm{mg} / \mathrm{kg}$ of neostigmine and $0.02 \mathrm{mg} / \mathrm{kg}$ of atropine. They were adequately ventilated with oxygen after extubation and were transferred to recovery room and then to post operative ward.

Heart rate was read from the ECG monitor. Systolic and diastolic blood pressure was recorded by indirect blood pressure measurement using a sphygmomanometer. Mean arterial pressure was calculated as diastolic pressure plus one-third of pulse pressure. Rate pressure product was calculated as the product of heart rate and systolic blood pressure.

Statistical analysis was done in stata IC 15 statistical software. Continuous data were summarised with mean and standard deviation or as median and inter quartile range. Catagorical variable was reported as percentage. The outcome measures were compared across the groups with chi-square tests and student's t test. Repeated measures ANOVA was used to compared the outcomes measures at different time points.

\section{Results}

In the total 45 patients we studied, the median age with inter quarter range of the patients was 36(28$45)$ years. There were more females in the study groups (80percent). The median weight of patients was $56(48-61) \mathrm{kg}$. Goitre was the major diagnosis in the patients included in the study (46.7\%) followed by carcinoma breast $(13.3 \%)$, fractures (8.9\%), cholecystitis (8.9\%),benign breast diseases (6.67\%) and LVDP(4.4\%). Ulnar nerve palsy, right inguinal hernia, swelling right forearm, carcinoma stomach and gynecomastia constituted the rest with one case each. The most frequent operative procedure was thyroidectomy followed by modified radical mastectomy.

The baseline characteristics of patients across the three groups were comparable [Table 1].

Table 1: Baseline characteristics across the groups

\begin{tabular}{llllll} 
& [ALL] N=45 & lignocaine N=15 & diltiazem N=15 & combined N=15 & p.overall \\
\hline $\begin{array}{l}\text { Age } \\
\text { Sex: }\end{array}$ & $36.0[28.0 ; 45.0]$ & $42.0[29.0 ; 49.5]$ & $33.0[30.0 ; 43.5]$ & $37.0[27.5 ; 40.5]$ & 0.584 \\
$\quad$ & & & & 0.340 \\
$\quad$ Female & $36(80.0 \%)$ & $14(93.3 \%)$ & $11(73.3 \%)$ & $11(73.3 \%)$ & \\
$\quad \begin{array}{l}\text { Male } \\
\text { Weight }\end{array}$ & $9(20.0 \%)$ & $1(6.67 \%)$ & $4(26.7 \%)$ & $4(26.7 \%)$ & \\
Preop Diagnosis: & $56.0[48.0 ; 61.0]$ & $56.0[48.0 ; 58.5]$ & $60.0[50.0 ; 61.5]$ & $55.0[52.5 ; 62.5]$ & 0.798 \\
$\quad$ Benign breast swelling & $3(6.67 \%)$ & $2(13.3 \%)$ & $0(0.00 \%)$ & $1(6.67 \%)$ & 0.432 \\
$\quad$ Breast ca & $6(13.3 \%)$ & $2(13.3 \%)$ & $4(26.7 \%)$ & $0(0.00 \%)$ & \\
Ca Stomach & $1(2.22 \%)$ & $0(0.00 \%)$ & $0(0.00 \%)$ & $1(6.67 \%)$ & \\
Cholecystitis & $4(8.89 \%)$ & $1(6.67 \%)$ & $1(6.67 \%)$ & $2(13.3 \%)$ & \\
Fractures & $4(8.89 \%)$ & $2(13.3 \%)$ & $1(6.67 \%)$ & $1(6.67 \%)$ &
\end{tabular}




$\begin{array}{lllll}\text { Gynacomastia } & 1(2.22 \%) & 0(0.00 \%) & 0(0.00 \%) & 1(6.67 \%) \\ \text { Goitre } & 21(46.7 \%) & 7(46.7 \%) & 6(40.0 \%) & 8(53.3 \%) \\ \text { LVDP } & 2(4.44 \%) & 0(0.00 \%) & 2(13.3 \%) & 0(0.00 \%) \\ \text { RIH } & 1(2.22 \%) & 0(0.00 \%) & 1(6.67 \%) & 0(0.00 \%) \\ \text { Swelling Right forearm } & 1(2.22 \%) & 0(0.00 \%) & 0(0.00 \%) & 1(6.67 \%) \\ \text { Ulnar N palsy } & 1(2.22 \%) & 1(6.67 \%) & 0(0.00 \%) & 0(0.00 \%) \\ \text { Surgery done: } & & & & \\ \text { Cholecystectomy } & 4(8.89 \%) & 1(6.67 \%) & 1(6.67 \%) & 2(13.3 \%) \\ \text { Gastrectomy } & 1(2.22 \%) & 0(0.00 \%) & 0(0.00 \%) & 1(6.67 \%) \\ \text { Herniorrhaphy } & 1(2.22 \%) & 0(0.00 \%) & 1(6.67 \%) & 0(0.00 \%) \\ \text { Laminectomy } & 2(4.44 \%) & 0(0.00 \%) & 2(13.3 \%) & 0(0.00 \%) \\ \text { lump excision } & 4(8.89 \%) & 2(13.3 \%) & 0(0.00 \%) & 2(13.3 \%) \\ \text { MRM } & 7(15.6 \%) & 2(13.3 \%) & 4(26.7 \%) & 1(6.67 \%) \\ \text { ORIF } & 4(8.89 \%) & 2(13.3 \%) & 1(6.67 \%) & 1(6.67 \%) \\ \text { Repair Ulnar nerve } & 1(2.22 \%) & 1(6.67 \%) & 0(0.00 \%) & 0(0.00 \%) \\ \text { Thyroidectomy } & 21(46.7 \%) & 7(46.7 \%) & 6(40.0 \%) & 8(53.3 \%)\end{array}$

Diastolic pressure varied at different time points in the groups studied within the groups and across the groups. Systolic and mean arterial pressure showed initial rise and later a downward trend across the group. There was a statistically signicant difference between the three groups studied $(\mathrm{p}<0.05)$ (figure 1,2 and 3).

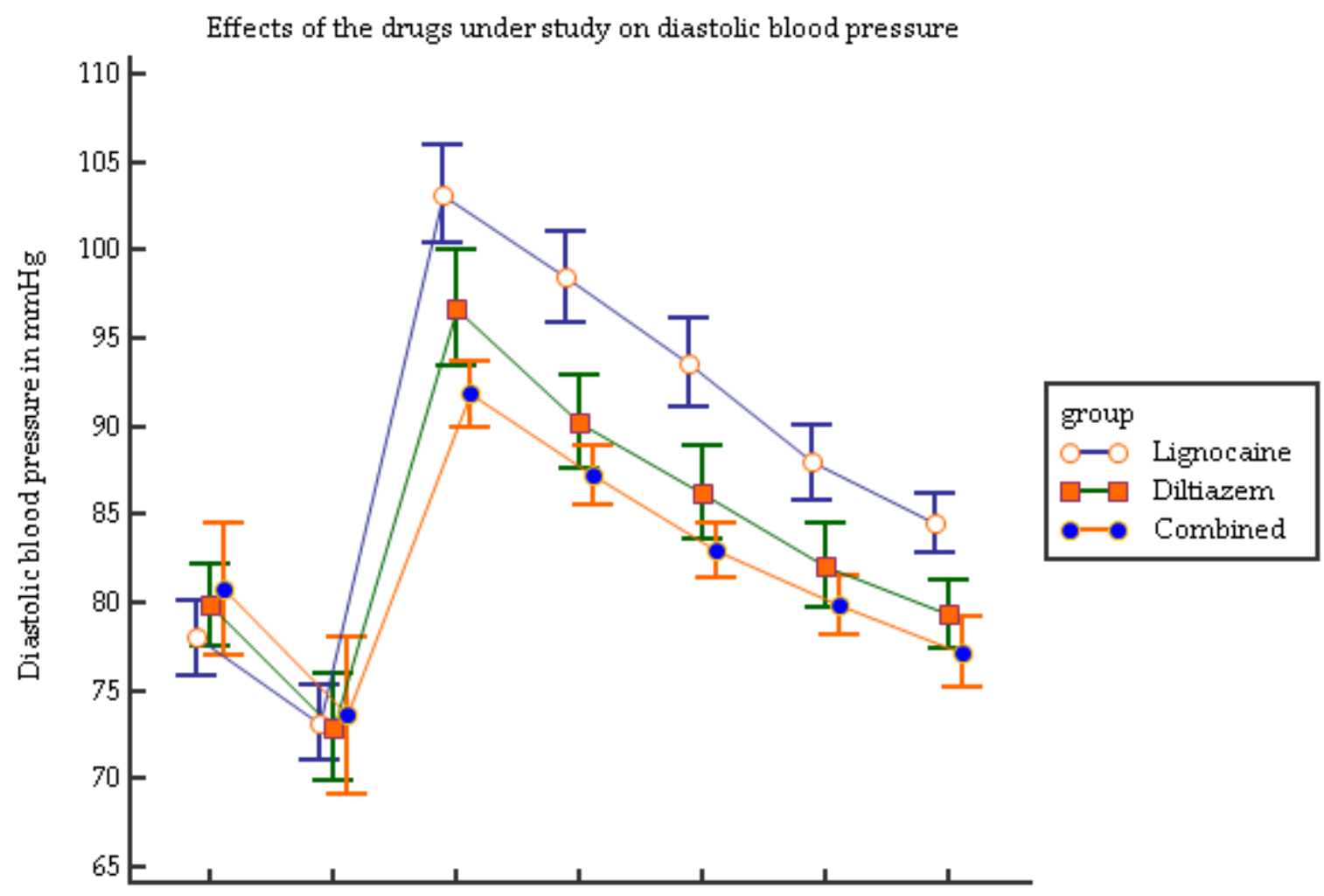

Pre.Induction.DBP Post.L.Scopy.DBP.1 Post.L.Scopy.DBP.3Post.L.Scopy.DBP.5.

Different time ponts at which diastolic blood pressue was measured

Figure 1: Effects of the drugs at different time points on diastolic pressure. 


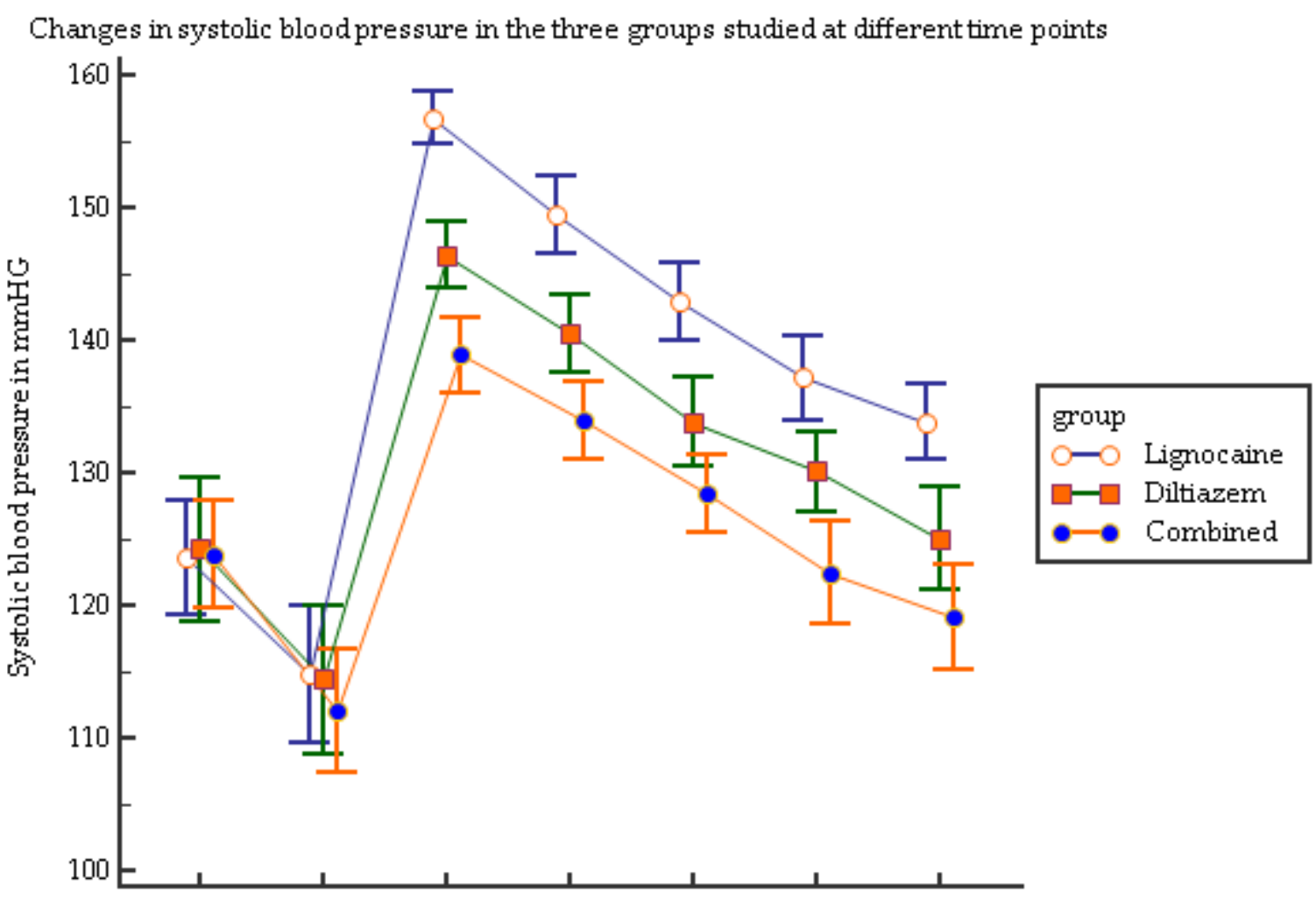

Pre.Induction.SBP Post.L.Scopy.SBP.1.Post.L.Scopy.SBP.3.Post.L.Scopy.SBP.5.

Different time periods at which systolic blood pressue was measured

Figure 2: Effects of drugs on systolic blood pressure at different time points.

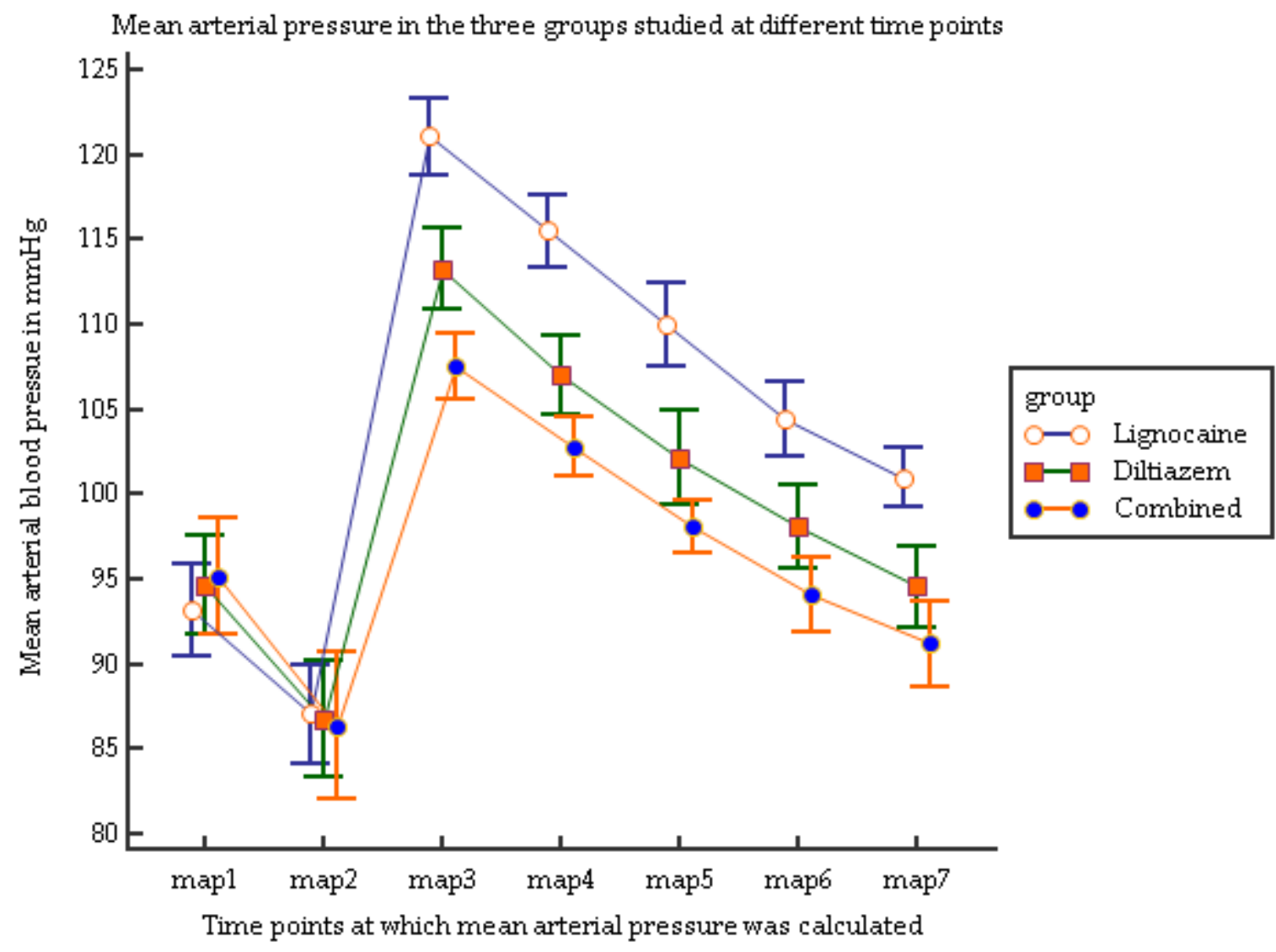

Figure 3: Effects of drugs on mean arterial pressure at different time points. 


\section{Discussion}

We conducted this study to test the hypothesis that circulatory responses to laryngoscopy and tracheal intubation in terms of changes in mean arterial pressure would be less in patients receiving diltiazem-lignocaine combination than in those receiving diltiazem or lignocaine alone.

The changes in the MAP in response to diltiazem is similar to that was reported in the literature. It tends to go down 20 to $40 \mathrm{sec}$ after diltiazem and is at the maximum level at 1.5 minutes in the literature. The result of our study is consistent with those studies in the literature ${ }^{20}$. The combined effect of lignocaine and dilitiazem results in clinically and statistically significant reduction the MAP. The study by Fujii et al showed that the combined dose is better than either one alone. Our results show similar trends. One of the limitations of our study was the low sample size. Moreover, the cohort design of this study limits the extrapolation of all results to a wider population.

The study revealed that SBP, DBP and MAP increased briefly after tracheal intubation in all patients who had received lignocaine, diltiazem or diltiazem plus lignocaine before intubation. The study also demonstrated that the peak values in SBP,DBP and MAP were significantly lower in the diltiazem - lignocaine combination group, thereby signaling its superiority in attenuating the stress response to laryngoscopy and intubation. The eventual attenuation of hemodynamic changes could be explained by the pharmacological characteristics of the drugs used.

\section{Reference}

1. Göksu S, Sen E. History of Intubation. Journal of Academic Emergency Medicine 2015; 14(1): 35 .

2. Robinson DH, Toledo AH. Historical development of modern anesthesia. Journal of Investigative Surgery 2012; 25(3): 141-9.

3. Baron SH, Kohlmoos HW. LXIX Laryngeal Sequelae of Endotracheal
Anesthesia. Annals of Otology, Rhinology \& Laryngology 1951; 60(3): 767-92.

4. Haas CF, Eakin RM, Konkle MA, Blank R. Endotracheal Tubes: Old and NewDiscussion. Respiratory care 2014; 59(6): 933-55.

5. Shribman A, Smith G, Achola K. Cardiovascular and catecholamine responses to laryngoscopy with and without tracheal intubation. BJA: British Journal of Anaesthesia 1987; 59(3): 295-9.

6. UDELSMAN R, NORTON JA, JELENICH SE, et al. Responses of the hypothalamic-pituitary-adrenal and reninangiotensin axes and the sympathetic system during controlled surgical and anesthetic stress. The Journal of Clinical Endocrinology \& Metabolism 1987; 64(5): 986-94.

7. Kayhan Z, Aldemir D, Mutlu H, Öğüş E. Which is responsible for the haemodynamic response due to laryngoscopy and endotracheal intubation? Catecholamines, vasopressin or angiotensin? European journal of anaesthesiology 2005; 22(10): 780-5.

8. Govindaiah MH, Suryanarayana VG, Vas P, Vlk JL, Chandra SBC. Can calcium and sodium channel blockers attenuate hemodynamic responses to endotracheal intubation? European Journal of General Medicine 2008; 5(4).

9. Forbes AM, Dally FG. Acute hypertension during induction of anaesthesia and endotracheal intubation in normotensive man. Br J Anaesth 1970; 42(7): 618-24.

10. Kovac AL. Controlling the hemodynamic response to laryngoscopy and endotracheal intubation. Journal of Clinical Anesthesia 1996; 8(1): 63-79.

11. Mort TC. Complications of emergency tracheal intubation: hemodynamic alterations-Part I. Journal of intensive care medicine 2007; 22(3): 157-65.

12. Kihara S, Brimacombe J, Yaguchi Y, Watanabe S, Taguchi N, Komatsuzaki T. 
Hemodynamic responses among three tracheal intubation devices in normotensive and hypertensive patients. Anesthesia \& Analgesia 2003; 96(3): 890-5.

13. Fox EJ, Sklar GS, Hill CH, Villanueva R, King BD. Complications related to the pressor response to endotracheal intubation. Anesthesiology 1977; 47(6): 524-5.

14. Abou-Madi M, Keszler H, Yacoub O. A method for prevention of cardiovascular reactions to laryngoscopy and intubation. Canadian Anaesthetists' Society journal 1975; 22(3): 316-29.

15. Stoelting RK. Circulatory response to laryngoscopy and tracheal intubation with or without prior oropharyngeal viscous lidocaine. Anesth Analg 1977; 56(5): 61821.

16. DAVIES MJ, CRONIN KD, COWIE RW. The prevention of hypertension at intubation. Anaesthesia 1981; 36(2): 147-51.

17. Mikawa K, Nishina K, Maekawa N, Obara H. Comparison of nicardipine, diltiazem and verapamil for controlling the cardiovascular responses to tracheal intubation. $\mathrm{Br}$ J Anaesth 1996; 76(2): 221-6.

18. Chen CC, Tsai PS, Yang LC, Jawan B, Lee JH. The comparative potency of intravenous nicardipine and verapamil on the cardiovascular response to tracheal intubation. Acta Anaesthesiol Sin 1996; 34(4): 197-202.

19. Mikawa K, Obara H, Kusunoki M. Effect of nicardipine on the cardiovascular response to tracheal intubation. $\mathrm{Br} \mathrm{J}$ Anaesth 1990; 64(2): 240-2.

20. Fujii Y, Saitoh Y, Takahashi S, Toyooka H. Combined diltiazem and lidocaine reduces cardiovascular responses to tracheal extubation and anesthesia emergence in hypertensive patients. Canadian journal of anaesthesia $=$ Journal canadien d'anesthésie 1999; 46(10): 952-6. 